\title{
Interventional bronchoscopy for tuberculous tracheobronchial stenosis
}

\author{
S-Y. Low, A. Hsu, P. Eng
}

Interventional bronchoscopy for tuberculous tracheobronchial stenosis. S-Y. Low, A. Hsu, P. Eng. (C) ERS Journals Ltd 2004.

ABSTRACT: This study investigated the use of interventional bronchoscopic techniques in the management of patients with symptomatic tracheobronchial stenosis from tuberculosis.

The current authors evaluated their experience with interventional bronchoscopic techniques in 21 consecutive patients at the Singapore General Hospital, Singapore, from November 1994 to March 2001. All patients underwent rigid bronchocopy using the Dumon rigid ventilating bronchosope under general anaesthesia. A combination of techniques was used (mechanical or balloon dilatation, Nd-YAG laser and stenting using the Dumon stent).

The mean \pm SD increase in luminal diameter of the tracheal lesions was from $4.5 \pm 2.5 \mathrm{~mm}$ pre-procedure to $11.9 \pm 1.7 \mathrm{~mm}$ post-procedure, whereas that for the mainstem bronchi stenosis was from $2.6 \pm 1.0 \mathrm{~mm}$ to $8.3 \pm 2.4 \mathrm{~mm}$. All patients had immediate relief of symptoms post-intervention. Two patients who presented with acute respiratory failure could be weaned off mechanical ventilation immediately postprocedure. At the end of the study period, 52\% (11 out of 21) remained asymptomatic.

Bronchoscopic intervention provided immediate symptomatic relief in all of the studied patients. However, repeated sessions may be required to maintain this improvement. It is concluded that interventional bronchoscopic techniques are useful in the management of patients with tracheobronchial stenosis from tuberculosis.

Eur Respir J 2004; 24: 345-347.
Dept of Respiratory and Critical Care Medicine, Singapore General Hospital, Singapore.

Correspondence: S-Y. Low

Dept of Respiratory and Critical Care Medicine Singapore General Hospital

Outram Road

Republic of Singapore 169608

Fax: 65 62271736

E-mail: gm31sy@sgh.com.sg

Keywords: Interventional bronchoscopy stenosis

stents

tuberculosis

Received: January 112004

Accepted after revision: May 92004
Tracheobronchial stenosis due to tuberculosis (TSTB) was first described in 1689 by Richard Morton, an English physician [1]. Despite the decline in pulmonary tuberculosis with the advent of effective chemotherapy, TSTB continues to be under-recognised and often misdiagnosed. Major airway obstruction from luminal stenosis can develop despite adequate anti-tuberculous drug treatment. Surgical treatment has been advocated as the best modality for management of such strictures [2]. However, some patients have long stenotic segments or severe stenosis at two levels, with compromised pulmonary reserve precluding curative surgery [3]. The current authors reviewed their experience with interventional bronchoscopy in the treatment of TSTB.

\section{Materials and methods}

A retrospective study of 21 patients with symptomatic TSTB, treated with interventional bronchoscopy at the Singapore General Hospital, Singapore, a tertiary care university-affiliated hospital, was conducted between November 1994 and March 2001. All patients' charts were reviewed and TSTB was diagnosed in all of the patients using flexible bronchoscopy. Active tuberculosis was defined as a positive acid-fast bacilli smear or mycobacterium culture from bronchial aspirate or bronchial biopsy. The rest of the patients had a definite past history of tuberculosis.

For editorial comments see page 343.
All patients underwent at least one interventional bronchoscopic procedure with Nd-YAG laser (Lasersonics, Division of Heraeus, Milpitas, CA, USA), mechanical or balloon dilatation, and/or stenting. This was performed in the operating room under general anaesthesia using the Dumon rigid ventilatory bronchoscope (Efer, La Ciotat, France). The main anaesthetic agents used were fentanyl $\left(2 \mu \mathrm{g} \cdot \mathrm{kg}^{-1}\right.$, where the maximum amount used was $50 \mu \mathrm{g}$ ) or alfentanyl $\left(5-20 \mu \mathrm{g} \cdot \mathrm{kg}^{-1}\right)$ and propofol $\left(2 \mathrm{mg} \cdot \mathrm{kg}^{-1}\right)$. Other agents included atropine $(0.6 \mathrm{mg})$, glycopyrrolate $(0.1-0.2 \mathrm{mg})$, midazolam $(1-5 \mathrm{mg})$ or lorazepam $(1 \mathrm{mg})$. Intubation with the largest fitting rigid bronchoscope was then performed. This was followed by dilatation using progressively larger diameter rigid brochoscopes. The Nd-YAG laser was used sparingly, mainly to resect fibrous bands. The laser was set in the intermittent mode at a power of $40 \mathrm{~W}$ and pulse duration of $0.4 \mathrm{~s}$. If stenosis was very severe, balloon dilatation preceded mechanical dilatation. Balloon dilatation was performed using a 7-French 15-mm oesophageal balloon (Microinvasive; Boston Scientific Corporation, Natick, MA, USA), which was inflated with normal saline until resistance was felt. Each inflation cycle was $20 \mathrm{~s}$ and this was repeated as necessary. Care was taken not to overinflate the balloon, in order to minimise the risk of airway perforation. The Dumon silicone stent (Axion, Aubaque, France) was the only type of stent used and it was inserted according to the original technique described by DUMON [4].

The luminal diameters of the airway pre- and posttreatment were visually assessed. Patients were followed-up 
within 1 month after discharge and regularly thereafter as per physician's discretion.

\section{Results}

Patients' baseline characteristics are summarised in table 1. In the current study, all of the patients had associated parenchymal tuberculous disease, and patients who had active tuberculosis had mycobacterium tuberculosis that was sensitive to first-line drugs. Patients' symptomatology is described in table 2. Two of the studied patients presented with acute respiratory failure. Most of the strictures $(50 \%)$ were in the left mainstem bronchus (fig. 1). In total, 16 out of the 21 patients $(76 \%)$ had one stricture each, whereas the other five patients had two strictures each. Of these five patients who had two strictures each, three patients had strictures in the trachea and left mainstem bronchus, whereas the remaining two patients had strictures in the trachea and right mainstem bronchus. The mean \pm SD luminal diameters of the tracheal and mainstem bronchi strictures were $4.5 \pm 2.5 \mathrm{~mm}$ and $2.6 \pm 1.0 \mathrm{~mm}$, respectively. A total of 11 patients $(52 \%)$ had stents inserted, of which eight received a single stent and three had two stents. Four patients failed stenting because one stent covered the right upper lobe orifice, and was hence removed, and the other three could not be deployed fully. The mean luminal diameter of the tracheal strictures increased by $164 \%$ from $4.5 \pm 2.5 \mathrm{~mm}$ pre-treatment to $11.9 \pm 1.7 \mathrm{~mm}$ post-treatment, whereas that of the mainstem bronchi increased by $219 \%$ from $2.6 \pm 1.0 \mathrm{~mm}$ to $8.3 \pm 2.4 \mathrm{~mm}$. Two patients who required emergency mechanical ventilation could be extubated immediately post-procedure. All patients achieved immediate symptomatic relief after their bronchoscopic intervention. Final outcomes at the end of the follow-up are shown in table 3 . One patient ultimately underwent a left pneumonectomy because of recurrent chest infections, despite

Table 1.-Baseline characteristics of the patients

\begin{tabular}{lc}
\hline Age yrs & $43.2 \pm 15.5$ \\
Patients n & 21 \\
$\quad$ Female & $16(76)$ \\
Male & $5(24)$ \\
Race & $17(81)$ \\
$\quad$ Chinese & $4(19)$ \\
$\quad$ Others & \\
Active tuberculosis & $3(14)$ \\
$\quad$ Received $<1$ month treatment before intervention & $6(29)$ \\
$\quad$ Intervention at the end of drug therapy & $12(57)$ \\
Inactive tuberculosis & \\
$\quad$ Patients n & $16.5(1-40)$ \\
$\quad$ Length of disease free interval &
\end{tabular}

Data are presented as mean $\pm \mathrm{SD}, \mathrm{n}(\%)$ and median (range).

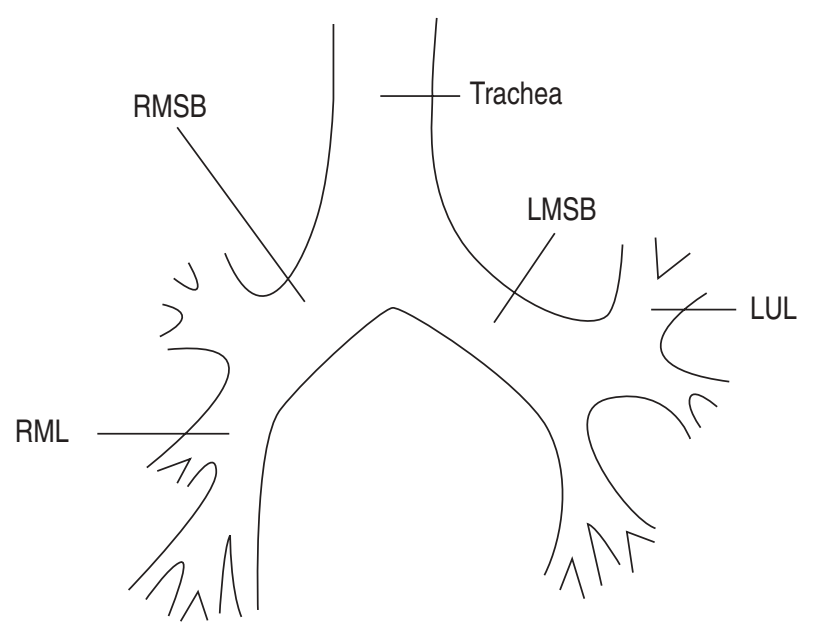

Fig. 1. - Strictures were located in the lung as follows: trachea $(n=7)$; left mainstem bronchus (LMSB; $n=13$ ); left upper lobe (LUL; $n=1$ ); right middle lobe (RML; $\mathrm{n}=1$ ); and right mainstem bronchus (RMSB; $n=4)$.

repeated interventional bronchoscopic procedures. Of the remaining 20 patients, 11 were asymptomatic. The median duration of follow-up was 25 months.

\section{Discussion}

TSTB is not uncommon. SALKIN et al. [5] reported the incidence of TSTB in patients with active pulmonary tuberculosis as $15.5 \%$, whereas So et al. [6] reported their incidence in Hong Kong to be $18 \%$. The impact of treatment with antituberculous chemotherapy and even steroids on the evolution of active tuberculous endobronchitis remains unclear [7-10]. The pathogenesis of this disease is thought to be from direct innoculation of tubercle bacilli into the bronchus [1].

The diagnosis of TSTB is usually delayed as chest radiography and flow/volume curves are insensitive [5, 7]. Flexible bronchoscopy remains the most useful modality for diagnosis and assessment if the diagnosis is suspected [11]. Of the 21 patients in the current study, $16(76 \%)$ were female. This predominance in the female sex has also been reported in Japan [2], Hong Kong [7] and Korea [10, 12]. It is postulated that this might be as a result of a narrower bronchus and the fact that females expectorate less, resulting in stasis of sputum containing tuberculous bacilli on the bronchial wall. As in other studies [2], the left mainstem bronchus was the most common site for TSTB in the studied patients. This could be because the left mainstem bronchus is easily compressed by the aortic arch. Lymph node tuberculosis is also more often

Table 2. - Symptoms at presentation

\begin{tabular}{|c|c|c|c|}
\hline \multirow[t]{2}{*}{ Symptom } & \multicolumn{3}{|c|}{ Patients } \\
\hline & All & Active & Inactive \\
\hline Patients $\mathrm{n}$ & 21 & 9 & 12 \\
\hline Cough & $18(86)$ & $9(100)$ & $9(75)$ \\
\hline Dyspnoea & $12(57)$ & $5(56)$ & $7(58)$ \\
\hline Loss of weight & $6(29)$ & $2(22)$ & $4(33)$ \\
\hline Fever & $5(24)$ & $1(11)$ & $4(33)$ \\
\hline Wheeze & $4(19)$ & $4(44)$ & $0(0)$ \\
\hline Acute respiratory failure requiring mechanical ventilation & $2(9.5)$ & $1(11)$ & $1(8)$ \\
\hline Duration of symptoms prior to diagnosis months & $3(0.2-48)$ & $4(0.5-24)$ & $2.5(0.2-48)$ \\
\hline
\end{tabular}

Data are presented as $\mathrm{n}, \mathrm{n}(\%)$ and median (range). 
Table 3.-Outcomes based on number of procedures

\begin{tabular}{|c|c|c|c|}
\hline Procedures $\#$ & Patients $n$ & $\begin{array}{l}\text { Reason for } \\
\text { repeat procedures }\end{array}$ & $\begin{array}{l}\text { Patients' final outcome } \\
\text { at the end of follow-up }\end{array}$ \\
\hline 1 & 14 & NA & $\begin{array}{l}7 \text { asymptomatic; } 2 \text { effort dyspnoea } \\
\text { (1 defaulted, } 1 \text { considering repeat procedure); } \\
4 \text { chronic cough ( } 2 \text { failed stenting, } 2 \text { stents in situ); } \\
1 \text { recurrent chest infections (considering surgery) }\end{array}$ \\
\hline 2 & 2 & $\begin{array}{l}\text { Restenosis; } \\
\text { stent migration and } \\
\text { granulation tissue }\end{array}$ & 1 asymptomatic; 1 recurrent chest infections (defaulted) \\
\hline 3 & 4 & $\begin{array}{l}\text { Restenosis and/or } \\
\text { stent migration }\end{array}$ & $\begin{array}{l}2 \text { asymptomatic; } 1 \text { recurrent chest infections } \\
\text { (underwent left pneumonectomy); } \\
1 \text { chronic cough (failed stenting) }\end{array}$ \\
\hline 5 & 1 & Granulation tissue & 1 asymptomatic \\
\hline
\end{tabular}

NA: not applicable. ${ }^{*}$ : $\mathrm{n}=35$.

noted on the left, making the left mainstem bronchus more vulnerable to pathological strictures.

The current patients were not suitable for surgical bronchoplasty as the primary modality of treatment because most had either multiple or long-segment involvement, or inadequate pulmonary reserve. In fact, two patients presented in extremis with acute respiratory failure requiring immediate intubation. They were weaned from mechanical ventilation immediately following the procedure. All patients had immediate amelioration of their symptoms and there was no mortality in the current study. In the long term, 52\% (11 out of 21) of the patients remained asymptomatic at the end of the follow-up period. Stents were used to reduce the risk of restenosis and were helpful in malacic airways, but repeat procedure was required in $19 \%$ (four out of 21 ) of the patients because of specific stent-related complications [13], including migration (two out of 21), granulation (one out of 21) or both (one out of 21). A major disadvantage of bronchoscopic management is that repeat sessions may be required [14]. This is similar to the study by WAN et al. [15], who reported their experience with interventional bronchoscopy in seven patients with TSTB. This illustrates the palliative nature of interventional bronchoscopic techniques for the management of airway stenoses. The current authors still feel that suitable patients should be considered for potentially curative bronchoplasty [16].

\section{Conclusions}

Interventional bronchoscopy offers immediate palliation of respiratory symptoms in cases with tracheobronchial stenosis due to tuberculosis. In a select subgroup, this improvement can be as dramatic as liberation from mechanical ventilation. This provides an alternative in the group of patients with severe tracheobronchial stenosis due to tuberculosis who are unsuitable for curative surgical resection.

\section{References}

1. Hudson EH. Respiratory tuberculosis: clinical diagnosis. In: Heaf ERG, ed. Symposium on tuberculosis. London, Cassell \& Co, 1957; pp. 321-464.
2. Watanabe $\mathrm{Y}$, Murakami S, Oda $\mathrm{M}$, et al. Treatment of bronchial stricture due to endobronchial tuberculosis. World J Surg 1997; 21: 480-487.

3. Hsu AAL, Eng P, Ong YY. Bronchoscopic management of severe airway stenosis caused by past tuberculosis. J Bronchol 1999; 6: 159-165.

4. Dumon JF. A dedicated tracheobronchial stent. Chest 1990; 97: $328-332$.

5. Salkin D, Cadden AV, Edson RC. The natural history of tuberculous tracheobronchitis. Am Rev Tuberc 1943; 47: 351-369.

6. So SY, Lam WK, Yu DYC. Rapid diagnosis of suspected pulmonary tuberculosis by fibreoptic bronchoscopy. Tubercle 1982; 63: 195-200.

7. Ip MS, So SY, Lam WK, Mok CK. Endobronchial tuberculosis revisited. Chest 1986; 89: 727-730.

8. Chan HS, Sun A, Hoheisel GB. Endobronchial tuberculosis: is corticosteroid treatment useful? A report of 8 cases and review of the literature. Postgrad Med J 1990; 66: 822-826.

9. Kim YH, Kim HT, Lee KS, Uh ST, Cung YT, Park CS. Serial fiberoptic bronchoscopic observations of endobronchial tuberculosis before and early after antituberculosis chemotherapy. Chest 1993; 103: 673-677.

10. Chung HS, Lee JH. Bronchoscopic assessment of the evolution of endobronchial tuberculosis. Chest 2000; 117: 385-392.

11. Hoheisel G, Chan BKM, Chan CHS, Chan KS, Teschler H, Costabel U. Endobronchial tuberculosis: diagnostic features and therapeutic outcome. Respir Med 1994; 88: 593-597.

12. Lee JH, Park SS, Lee DH, Shin DH, Yang SC, Yoo BM. Endobronchial tuberculosis. Clinical and bronchoscopic features in 121 cases. Chest 1992; 102: 990-994.

13. Bolliger CT, Probst R, Tschopp K, Soler M, Perruchoud AP. Silicone stents in the management of inoperable tracheobronchial stenoses: indications and limitations. Chest 1993; 104: 1653-1659.

14. Brichet A, Verkindre C, Dupont J, et al. Multidisciplinary approach to management of postintubation tracheal stenoses. Eur Respir J 1999; 13: 888-893.

15. Wan IY, Lee TW, Lam HCK, Abdullah V, Yim AP. Tracheobronchial stenting for tuberculous airway stenosis. Chest 2002; 122: 370-374.

16. Kato R, Kakizaki $\mathrm{T}$, Hangai N, et al. Bronchoplastic procedures for tuberculous bronchial stenosis. J Thorac Cardiovasc Surg 1993; 106: 1118-1121. 